\title{
SIR GODFREY NEWBOLD HOUNSFIELD Y LA TOMOGRAFIA COMPUTADA, SU CONTRIBUCION A LA MEDICINA MODERNA
}

\section{Dr. Enrique Bosch 0.}

Servicio de Radiología. Clínica Alemana. Santiago.

Abstract: Sir Godfrey Hounsfield, who died on August 12, 2004 , led the team which developed Britain's first big solid-state computer before inventing the computerized axial tomography scanner for use in clinical diagnosis. In recognition of the latter achievement he was awarded the 1979 Nobel Prize for Physiology or Medicine. His invention revolutionized almost all specialties in Medicine, up to our days. The history of his invention and some insights on his personal life are presented.

Key words: Computed Tomography, Godfrey N. Hounsfield.

Resumen: Sir Godfrey Hounsfield -recientemente fallecido- revolucionó la medicina con la tomografía computada o escáner. Su invento es considerado por muchos como uno de los más importantes del siglo XX y lo hizo merecedor del premio Nóbel en 1979. El significado de su invención y algunos aspectos biobliográficos son revisados.

Palabras claves: Godfrey N. Hounsfield, Tomografía computada.

\section{Introducción}

No es exageración decir que en el diagnóstico por imágenes hay un antes y un después de la creación de la tomografía computada o escáner. La capacidad de poder ver en mejor forma, con más precisión y menor invasión el interior del cuerpo humano se lo debemos en gran parte a Sir Godfrey Hounsfield (Figura 1), inglés -en gran parte autodidacta- cuya creación le valió el Premio Nóbel de medicina o fisiología en $1979^{(1)}$.

Hounsfield falleció el 12 de Agosto pasado en Londres a los 84 años y su muerte fue consignada en los principales diarios del mundo que le dedicaron columnas y reportajes ${ }^{(2-4)}$.

Bosch E. Sir Godfrey Newbold Hounsfield y la tomografía computada, su contribución a la medicina moderna. Rev Chil Radiol 2004; 10: 183-185.

Correspondencia: Dr. Enrique Bosch O. Clínica Alemana. Vitacura 5951. Santiago de Chile.
Figura 1. Sir Godfrey N. Hounsfield (1919-2004).

Como muchos otros científicos importantes, su nombre es poco conocido fuera del ambiente radiológico, pese a que su creación, en constante evolución, aún sigue revolucionando a numerosas especialidades de la medicina. Su invento es considerado por muchos como uno de los más importantes del siglo $X X^{(5)}$, comparándolo a lo que en su época significó el descubrimiento de los rayos $\mathrm{X}$ por Roentgen.

\section{Motivaciones iniciales}

Después de la primera guerra mundial su padre adquiere una granja en Newark, Nottinghanshire donde nace en Agosto 28, 1919. Fue el lugar ideal para un niño inquieto y de gran imaginación, el menor de cinco hermanos, para sus primeras invenciones. Diferentes maquinarias agrícolas son su primera motivación.

Su interés lo lleva hacia aparatos eléctricos construyendo amplificadores y grabadoras y con un amigo del colegio logran instalar un cinematógrafo al lado de su casa(1). 
Desarrolla además en esta etapa experimentaciones sobre vuelo lanzándose desde montones de heno en rudimentarios planeadores construidos por el mismo. En el colegio demuestra un moderado y fácil entusiasmo por física y matemáticas.

El interés en aeroplanos lo lleva durante la segunda guerra mundial a enrolarse como reservista voluntario en la real fuerza aérea (RAF), donde adquirió experiencia en electrónica al trabajar en radares. Su aporte lo lleva a ser instructor de la Escuela de Radar de la RAF. El reconocimiento de su labor por parte de sus superiores lo llevan a la Faraday House Electrical Engineering College de Londres donde estudia Ingeniería eléctrica.

En 1951, se incorpora a la firma EMI Limited participando en el desarrollo de nuevos sistemas de radar y de armas guiadas.

\section{Camino a la tomografía computada (TC)}

En su trabajo tempranamente se interesó por los computadores, liderando el equipo que construyó el primer computador con transistores del Reino Unido en 1958, siendo posteriormente trasladado por EMI a sus laboratorios de investigación.

En los años 60 aplicó los conocimientos adquiridos al desarrollo del escáner, dándonos con ello una forma diferente de obtener y registrar la interacción de los Rayos X con el cuerpo. De esta forma pudimos visualizar los distintos órganos y tejidos, con el giro el tubo en el eje axial y procesamiento de la información con detectores y amplificadores de mayor sensibilidad que la placa radiográfica convencional disponible hasta ese momento.

La radiología convencional era la principal herramienta de diagnóstico por imágenes, y tenía numerosas limitaciones. No se podía representar, en una película de dos dimensiones toda la información contenida en un objeto que posee tres, quedando las diferentes estructuras superpuestas. Además discriminaba solo entre tejidos de densidad muy diferente como lo son el aire, agua, hueso, grasa y tampoco era capaz de separar en forma cuantitativa las distintas densidades de las estructuras exploradas por el haz de rayos X. La placa radiográfica sólo es capaz de registrar la absorción media de los tejidos atravesados.

La tomografía computada introduce el cambio ya que puede medir la atenuación o absorción del haz de rayos cuando pasa a través de secciones del cuerpo y lo hace desde cientos de diferentes ángulos. Con estas mediciones, los computadores pueden reconstruir imágenes del interior del cuerpo. El paradigma fue comprender, que al escanear un objeto desde muchos ángulos, era posible extraer toda la información contenida en él.

Este concepto ya había sido publicado por
Allan Cormack ${ }^{(6)}$, físico sudafricano, en los años 1963 y 1964, pero sus estudios no tuvieron un resultado práctico, probablemente por las dificultades de los computadores de su época para realizar todos los cálculos necesarios en un tiempo razonable, pero es sin duda Sir Godfrey Hounsfield la figura central en el desarrollo del tomógrafo computado. En forma totalmente independiente de Cormack, desarrolló un prototipo y construyó el primer equipo de TC para uso clínico, que permitía examinar el cráneo y su contenido (Figuras 2,3).

Los primeros resultados clínicos se publicaron en la primavera europea de 1972, sorprendiendo a la comunidad médica. Procesos patológicos que previamente solo podían demostrarse, en forma indirecta, eran ahora demostrados en forma directa. Pocos descubrimientos médicos han recibido una aceptación tan inmediata y entusiasmaron tanto como la tomografía computada ${ }^{(7)}$ revolucionando el trabajo médico en el mundo entero.

Los cinco primeros equipos fabricados fueron instalados en el Reino Unido y Estados Unidos. Luego se sucedieron rápidamente nuevas generaciones de ellos con notables avances, que expandieron sus aplicaciones, permitiendo no sólo el estudio del cráneo y cerebro, sino también del resto del cuerpo.

El primer escáner en Chile se instaló en Santiago en 1977, y al igual que en el resto del mundo, el número de equipos creció rápidamente.

Sir Godfrey Hounsfield obtuvo el premio Nóbel de Fisiología o Medicina en 1979, compartiéndolo con Allan Cormack. En el discurso de presentación del comité del Nóbel(8), se destacó que previo al escáner, "las radiografías de la cabeza mostraban sólo los huesos del cráneo, pero el cerebro permanecía como un área gris, cubierto por la neblina. Súbitamente la neblina se ha disipado".

En su discurso de aceptación del premio ${ }^{(9)}$, se refirió al futuro de esta técnica, prediciendo muchos de los avances que seguirían, e incluso habló de la

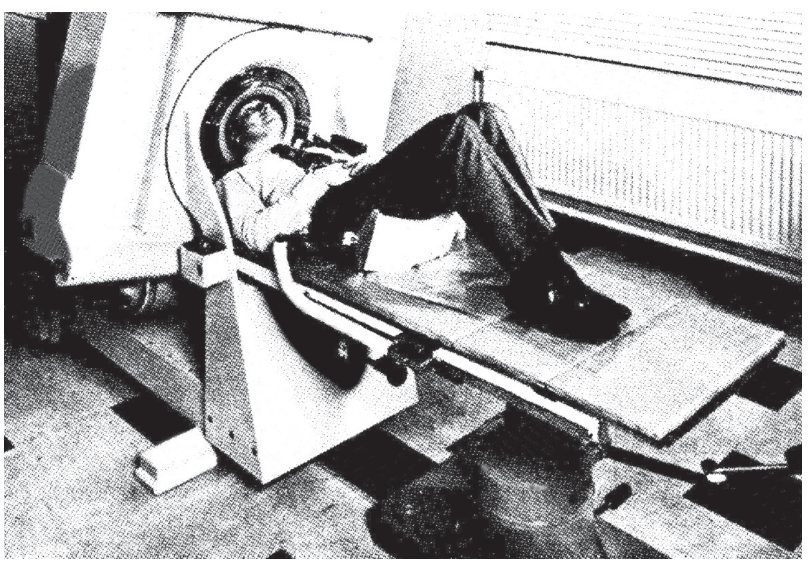

Figura 2. Primer prototipo de escáner clínico para cerebro instalado en el Hospital Atkinson Morley's. Londres. 


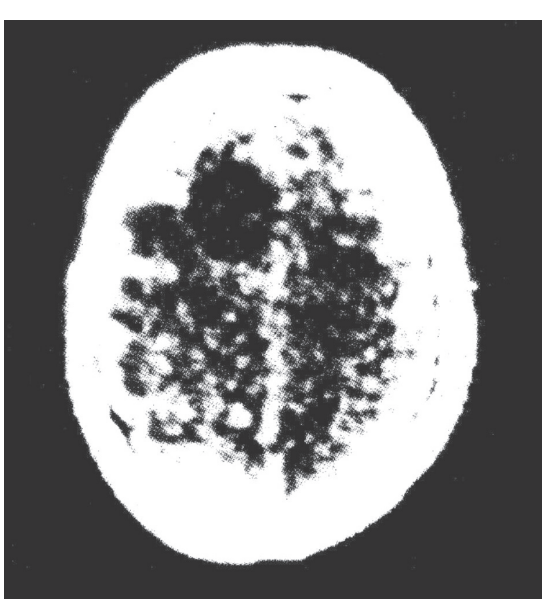

Figura 3.

Primera

imagen clínica

obtenida con

tomógrafo

computado

prototipo.

posibilidad de examinar las arterias coronarias, bajo lo que llamó "condiciones especiales". Hoy esas condiciones son una realidad y permiten, entre muchos otros estudios, evaluarlas en forma rutinaria y no invasiva. En ese mismo discurso se refirió a los fundamentos de la resonancia magnética, que por esos años también se iniciaba como una revolucionaria herramienta diagnóstica. Visualizó que ambas técnicas, serían complementarias, contribuyendo a importantes avances, en una nueva era del diagnóstico médico.

Permaneció en EMI como jefe del área de investigación médica, retirándose oficialmente en 1986, pero continuó trabajando como consultor de dicha empresa y de varios hospitales del Reino Unido. El interés del público por su invención complicó a este hombre sencillo, que disfrutaba caminando por las montañas, sin un plan definido. Recibió numerosos premios y distinciones entre ellas ser nombrado caballero y ser distinguido con el McRobert Award considerado como el premio Nóbel de ingeniería, un mérito indiscutible para alguien sin estudios universitarios.

En su recuerdo y como homenaje, utilizamos las unidades Hounsfield, para definir la densidad de los tejidos estudiados en tomografía computada.

\section{Conclusión}

Los avances continúan hasta hoy y especialmente en los últimos años, a un ritmo vertiginoso. Estos han sido posibles gracias al desarrollo de nuevos algoritmos de reconstrucción de las imágenes, nuevos desarrollos técnicos y al desarrollo paralelo de equipos computacionales que pueden procesar cada vez mayor información, en un tiempo menor. Como un indicador de estos cambios, los equipos en la década de los 80 , efectuaban un corte de $1 \mathrm{~cm}$ de grosor, con un tiempo de giro de 1 segundo y requerían 20-30 segundos, para reconstruir la imagen de dicho corte. Actualmente existen equipos capaces de efectuar 64 cortes, submilimétricos, en 1/2 segundo, todos los cuales son reconstruidos en forma instantánea. Entre las muchas ventajas de los nuevos equipos está, el permitir reconstruir los "volúmenes de datos" adquiridos, en cualquier plano del espacio, dándole una capacidad multiplanar, mejorando así nuestra habilidad para detectar y entender las enfermedades ${ }^{(10)}$.

Millones son los pacientes que se benefician cada día con el invento de Sir Godfrey Hounsfield, que permitió objetivar mejor las alteraciones que las enfermedades producen en el organismo, contribuyendo a un diagnóstico más precoz, preciso y a evaluar los tratamientos efectuados. De esta forma sustituyó y eliminó numerosos otros estudios diagnósticos de menor rendimiento y permitió el crecimiento de la radiología intervencional, o cirugía mínimamente invasiva, al utilizarlo como guía de agujas o catéteres para obtener muestras de tejidos o vaciar abscesos, sustituyendo en ambos casos a la cirugía tradicional.

Con su invento, Sir Godfrey Hounsfield transformó la especialidad de la radiología, expandiendo sus áreas de influencia, convirtiendo nuestro trabajo en un apoyo y servicio a las demás especialidades médicas ${ }^{(11)}$.

\section{Bibliografía}

1. Press Release. Presentation Speech. Godfrey N Hounsfield-Autobiography. Nobel Prize in Physiology or Medicine. October 1979. www.nobelprize.org.

2. Pearce J. Sir Godfrey Hounsfield, who helped develop the CAT scanner, dies at 84. New York Times. 2004; August 20.

3. Sir Godfrey Hounsfield. Obituary. The Times. 2004; August 18.

4. Sir Godfrey Hounsfield. Daily Telegraph. 2004; August 17.

5. The editors. Editorials. Looking Back On The Millennium In Medicine. The New England Journal of Medicine. 2000; 342: $42-49$.

6. Cormack AM. Representation of a function by its line integrals with some radiological applications J App Phys 1964; 35: 2908-2913.

7. Hounsfield GN: Computerized transverse axial scanning (tomography): Part 1. Description of system. Br J Radiol 1973; 46:1016-1022.

8. The Nobel Prize in Physiology or Medicine 1979 Presentation Speech by Professor Torgny Greitz of the Karolinska Medico-Chirurgical Institute. www.nobelprize.org

9. Hounsfield GN: Computed Medical imaging: Nobel lecture, December 8, 1979; Comp Assist Tomogr 1980; 4: 665-674.

10. Schoepf UJ, Becker CR, Bernd M, et al. CT of Coronary Artery Disease. Radiology 2004; 232: 18-37.

11. Bosh E. Hounsfield: El inventor del escáner. EI Mercurio 2004; Noviembre 14. 